\title{
Knowledge, perception, practices and barriers of healthcare professionals in Bosnia and Herzegovina towards adverse drug reaction reporting
}

\author{
Maša Amrain ${ }^{1 *}$, Fahir Bečić ${ }^{2}$
}

'Boehringer Ingelheim BH d.o.o., Regulatory Affairs Department, Sarajevo, Bosnia and Herzegovina, ${ }^{2}$ Department of Pharmacology, University of Sarajevo Faculty of Pharmacy, Sarajevo, Bosnia and Herzegovina

\begin{abstract}
Introduction: Pharmacovigilance is an arm of patient care. No one wants to harm patients, but unfortunately any medicine will sometimes do just this. Underreporting of adverse drug reactions by healthcare professionals is a major problem in many countries. In order to determine whether our pharmacovigilance system could be improved, and identify reasons for under-reporting, a study to investigate the role of health care professionals in adverse drug reaction (ADR) reporting was performed.

Methods: A pretested questionnaire comprising of 20 questions was designed for assessment of knowledge, perceptions, practice and barriers toward ADR reporting on a random sample of 1000 healthcare professionals in Bosnia and Herzegovina.
\end{abstract}

Results: Of the 1000 respondents, 870 (87\%) completed the questionnaire. The survey showed that $62.9 \%$ health care professionals would report ADR to the Agency for Medicinal Products and Medical Device of Bosnia and Herzegovina (ALMBIH). Most of surveyed respondents has a positive perception towards ADR reporting, and believes that this is part of their professional and legal obligation, and they also recognize the importance of reporting adverse drug reactions. Only small percent (15.4\%) of surveyed health care professionals reported adverse drug reaction.

Conclusions: The knowledge of ADRs and how to report them is inadequate among health care professionals. Perception toward ADR reporting was positive, but it is not reflected in the actual practice of ADRs, probably because of little experience and knowledge regarding pharmacovigilance. Interventions such as education and training, focusing on the aims of pharmacovigilance, completing the ADR form and clarifying the reporting criteria are strongly recommended.

Keywords: knowledge; health care professionals; adverse drug reaction (ADR); pharmacovigilance; Bosnia and Herzegovina

\footnotetext{
*Corresponding author: Maša Amrain,

Boehringer Ingelheim BH d.o.o.,

Regulatory Affairs department Sarajevo,

Bosnia and Herzegovina,

Phone:+38762849727,

E-mail: masa.amrain@boehringer-ingelheim.com
}

Submitted August 32014 / Accepted September 202014

\section{INTRODUCTION}

Any drug/medicine during its normal therapeutic use has a potential to produce adverse drug reaction(s) (ADRs). ADRs contribute to a significant number of morbidity and mortality all over the world (1). It has been estimated that around 
2.9-5.6\% of all hospital admissions are due to ADRs and as many as $35 \%$ of hospitalized patients experience an ADR during their hospitalization (2). The economic burden of ADRs is also considerable; for example in the United States, annual total cost of $\$ 47.4$ billion for 8.7 million drug related admissions were reported (3).

Many developed countries have strong and efficient pharmacovigilance systems. Good pharmacovigilance system will identify the risks and the risk factors in the shortest possible time so that harm can be avoided or minimized (4). These systems among other use spontaneous reporting to collect and analyze adverse events associated with the use of drugs. Though this process is not perfect, it can provide evidence that can be used to establish regulatory action to protect public health, and in addition it is fast and cost-efficient method.

Several studies (5) have indicated a variety of obstacles to the spontaneous reporting of ADRs, such as lack of time $(6,7)$ different care priorities $(7)$, uncertainty about the drug causing the ADR (7-10), difficulty in accessing reporting forms (6), lack of awareness of the requirements for reporting $(7,10)$ and lack of understanding of the purpose of spontaneous reporting systems (6).

Physicians, pharmacists, dentists and nurses are in a position to play a major key role in pharmacovigilance programs $(11,12)$ but underreporting is very common, with an estimated median underreporting rate (defined as percentage of ADRs detected from intensive data collection that were not reported to relevant spontaneous reporting systems) of $94 \%$ (5).

Pharmacovigilance is still in its infancy in Bosnia and Herzegovina $(\mathrm{BiH})$ and there exists very limited knowledge about this discipline. In the period after the war, until the establishment of the Agency for Medicinal Products and Medical Devices of Bosnia and Herzegovina (ALMBIH) there were two regional centers where health care professionals (HCP) were able to report ADR. In the Federation of Bosnia and Herzegovina $(\mathrm{FBiH})$, this was a Center for Medicine at the Institute of Pharmacology, Faculty of Medicine in Sarajevo, while in the Republic of Srpska (RS) this was Drug Agency RS.

The ALMBIH was established in accordance with the Medicinal Products and Medical Devices Act of Bosnia and Herzegovina as the competent body responsible for the field of medicinal products and medical devices manufactured and used in $\mathrm{BiH}$. It began operating on May 1 2009. (13). ADR reporting in $\mathrm{BiH}$ is closely linked to economic problems in the local healthcare system, which is still being developed. The level of ADR reporting is inadequate despite the fact that information on the safety of medicinal products is of vital importance and despite the fact that reporting on adverse effects to the ALMBiH is a legal obligation. This obligation is defined in the Book of rules on the manner of reporting, collecting and following adverse effects of the medicinal product, in Article 11 (14) "medicinal product manufacturers, health care institutions and health care professionals (medicinal doctors, dentists, pharmacists, health technicians, nurses) are under the obligation to report to the Agency any suspicion about the adverse effects of a medicinal product".

The objective of this study was to gain insight into the perceptions, practices and barriers of HCP in $\mathrm{BiH}$ with respect to the reporting of $\mathrm{ADR}$ and pharmacovigilance.

\section{METHODS}

Knowledge, perceptions, practices and barriers of healthcare professionals about terms related to pharmacovigilance and reporting of adverse drug reactions have been tested with the help of a structured questionnaire that was distributed in person (the response to the survey was either obtained at the same time or collected at a later time) or via e-mail. A random sample of healthcare professionals (doctors of different specialties, pharmacist, dentists, technicians and nurses) were randomly selected from different hospitals and health centers, distributed over all regions of $\mathrm{BiH}$. As there is no common database of $\mathrm{HCP}$ in $\mathrm{BiH}$ there is no guarantee they represent country profile. The questionnaire included issues addressed in previous studies examining the same problem $(6-8,15-20)$, but was modified by taking into account local features and simplified to exclude non relevant questions. A draft questionnaire was pretested by administering it to 6 healthcare professionals, which consisted of three pharmacists, two physicians and two dentists. Based on their comments and suggestions a final questionnaire was 
prepared for conducting the survey. The final version consisted of five sections containing 20 questions. Among these questions, 5 items were related to the demographical and professional profiles, 3 to the knowledge, 3 to the perception, 2 were related to practice aspects and the remaining 7 items were related to the barriers. Except questions related to demographical and professional profile, questions were worded as a series of statements and the healthcare professionals were asked to indicate their agreement or disagreement on a 4-point Likert scale from 'strongly agree' to 'strongly disagree'.

This questionnaire survey was conducted during January 2012 to September 2012.

\section{Statistical analysis}

The collected data were entered into the Excel table and then analyzed using the IBM Statistical Package for Social Sciences (SPSS) version 20.0.

\section{RESULTS}

A total of 1000 questionnaires were distributed/ sent and 870 were returned completed, so all analyses were therefore made based on the 870 filled in questionnaires. The demographic and professional details of the respondents are shown in Table 1.

TABLE 1. Demographic and professional details of HCP

\begin{tabular}{llcc}
\hline & & \multicolumn{2}{c}{ Respondents } \\
\cline { 3 - 4 } Sex & & Number & $\%$ \\
\hline \multirow{3}{*}{ Profession } & Male & 870 & 100.0 \\
& Female & 243 & 27.9 \\
& Doctor & 627 & 72.1 \\
& Pharmacist & 258 & 29.7 \\
& Dentist & 143 & 16.4 \\
Work experience & 61 & 7.0 \\
& Nurse & 234 & 26.9 \\
& Technician & 174 & 20.0 \\
& $0-5$ year & 181 & 20.8 \\
& 6-10 year & 186 & 21.4 \\
& $11-20$ year & 206 & 23.7 \\
Entity & 21-30 year & 201 & 23.1 \\
& More than 30 year & 95 & 10.9 \\
& FBiH & 644 & 74.0 \\
& RS & 225 & 25.9 \\
& Brčko district & 1 & 0.1 \\
\hline
\end{tabular}

Most respondents were in Sarajevo (36.9\%), Tuzla $(22.8 \%)$ and Banja Luka (21.5\%). The remaining $18.8 \%$ of respondents were interviewed in other cities.

The majority of respondents (84. 6\%, i.e. 736 respondents) provided a negative response to the question "Have you ever reported an adverse drug reaction?" and only $15.4 \%$ (133 respondents) gave a positive response. $17.1 \%$ of them were physicians, $25.2 \%$ pharmacists, $6.6 \%$ dentists, $10.7 \%$ nurses and $13.8 \%$ technicians.

$62.9 \%$ of respondents recognize the Agency for Medicinal Products and Medical Devices of Bosnia and Herzegovina as the institution to which ADR of a medicinal product are to be reported. A further question we used to establish how informed the respondents are on the issue pharmacovigilance was whether they agreed with the assertion that ADR reporting forms are available. Pharmacists in many cases $(43.4 \%)$ claimed that the reporting forms are available, while not even a fifth of the respondents from the other categories agreed that this was the case.

Asked about their experience in filling out the ADR reporting form, $46.6 \%$ of the respondents from our sample stated that they do not have enough experience.

Almost three quarters $(79.1 \%)$ of respondents report ADR only if they are certain that it is linked to a specific medicinal product, $80.5 \%$ of respondents would consult with a physician/pharmacist/ dentist before reporting an ADR and only $4.1 \%$ do not share such a view.

It was found out from the result that almost all health providers agree towards the fact that reporting about ADR is part of their ethical (83.2\%) and legal $(82.2 \%)$ duty and that the science of pharmacovigilance is important $(92.6 \%)$.

Several factors were reported that negatively affected health care professionals' willingness to report. Table 2 lists factors that may act as deterrents to reporting by HCP.

\section{DISCUSSION}

This is the first survey, which we are aware of, to explore healthcare professionals knowledge, attitude, 
TABLE 2. Barriers to spontaneous reporting of ADRs

\begin{tabular}{lcccc}
\hline Barriers & \multicolumn{4}{c}{ Level of agreement (percentage) } \\
\cline { 2 - 5 } & Agree & $\begin{array}{c}\text { Partially } \\
\text { Agree }\end{array}$ & $\begin{array}{c}\text { Partially } \\
\text { disagree }\end{array}$ & Disagree \\
\hline $\begin{array}{l}\text { Reporting form } \\
\text { too complicated }\end{array}$ & 19.9 & 31.3 & 10.8 & 37.0 \\
$\begin{array}{l}\text { Reporting ADRs is } \\
\text { time consuming }\end{array}$ & 20.2 & 29.5 & 10.6 & 38.6 \\
$\begin{array}{l}\text { Difficult to admit } \\
\text { harm to patient }\end{array}$ & 26.6 & 27.7 & 9.2 & 36.4 \\
Fear of liability & 10.6 & 14.9 & 12.3 & 62.1 \\
$\begin{array}{l}\text { Insufficient clinical } \\
\text { knowledge }\end{array}$ & 13.1 & 19.2 & 10.3 & 57.2 \\
$\begin{array}{l}\text { Patient confidence } \\
\text { No motivation }\end{array}$ & 11.3 & 26.4 & 14.4 & 47.5 \\
\hline
\end{tabular}

perceptions and their barriers towards ADR reporting and pharmacovigilance in $\mathrm{BiH}$. The survey response rate was good (87\%).

Although the majority of healthcare professionals correctly responded to whom they should report adverse reactions, it needs to be noted that almost a third gave a wrong answer to this question. This is a relatively high percentage of healthcare professionals who failed to provide a correct answer. This also indicates that although more than 4 years have passed since the establishment of ALMBIH, not enough publicity has been given to this. Results of the survey in one of Istanbul's districts show that only $6.7 \%$ of pharmacists would send their reports to the national pharmacovigilance center (TUFAM), i.e. the correct address (21).

It has transpired that the unavailability of $\mathrm{ADR}$ reporting forms is significantly impacting the informedness of healthcare professionals, despite the fact that the forms are also on the ALMBIH website, as well as in the Register of Medicinal Products. The Rhode Island survey (22) provided similar results with $38 \%$ of physicians stating that they do not know where to find the forms and that this is why they were not reporting adverse reactions.

Asked about their experience in filling in the ADR reporting form, just under $50 \%$ of healthcare professionals included in the survey stated that they do not have enough experience.

The majority of healthcare professional in our survey have never reported an adverse reactions.
The percentage of reported adverse reactions is very low when compared to the number of adverse reactions reported by physicians in Great Britain (23), the Netherlands (24), Spain (25) and China (26). Differences in the number of reported ADRs can be attributed to the priority, care and commitment to pharmacovigilance on the part of the national governments of those countries. Regulatory bodies in $\mathrm{BiH}$ should also adopt such an approach. It is evident that pharmacovigilance activities in $\mathrm{BiH}$ are not adequately presented or advertised.

Questions concerning perception focused on the general perception of healthcare professionals regarding the standard aspects of ADR reporting. The survey has shown that healthcare professionals have a positive attitude towards ADR reporting. The vast majority consider reporting a part of their professional obligations, as well as an integral part of the code of ethics. These results are largely similar to the results of surveys carried out among pharmacists working in pharmacies in cities in the Netherlands (27) and Great Britain (28).

Although the majority of healthcare professionals covered by the survey expressed a proper and positive attitude towards ADR reporting, actual hands-on experience in reporting is still lacking. Similar responses were obtained through three surveys conducted in India (29-31) where both the knowledge and a positive attitude exist, but adverse reactions are still not being reported.

Even though the Book of Rules on Adverse Effects (14) stipulates that all adverse effects are to be reported, even when a link has not been established, healthcare professionals have stressed that they must be certain that a link between a medicinal product and an adverse effect does exist. This is in line with the conclusions from earlier surveys conducted among pharmacists and physicians in other countries $(10,32,33)$ who expressed concern over showing a lack of knowledge because they are uncertain whether a medicinal product has caused an adverse reaction or not. This problem needs to be approached carefully and educational programs need to be organized to alleviate the anxiety of healthcare professionals and strengthen their confidence in reporting adverse reactions. 
A large percentage of healthcare professionals have indicated that they would consult a colleague (physician/pharmacist/dentist) before reporting an adverse effect even though they are not under an obligation to do so. This could indicate a lack of confidence in their own knowledge, and perhaps even fear of legal consequences. Similar results came out of previous surveys $(27,28)$. Colleagues should not be consulted in relation to reporting an adverse effect because that could be an obstacle to reporting and lead to a situation where the person reporting the adverse effect is dependent on someone else's opinion.

It is widely accepted that reporting on adverse effects is linked to a high degree of side effects not being reported, however, it is difficult to assess the scope of this problem. It is estimated that $90-95 \%$ of adverse effects go unreported (34). To identify the reasons for underreporting, several studies were conducted where different authors investigated the knowledge, attitudes and practices of healthcare professionals toward the ADR reporting. According to the findings of the studies $(1,5,26,32)$ healthcare professionals mentioned different factors that have contributed towards their underreporting: lack of awareness of the requirement for reporting, lack of resources for surveillance and reporting, time-consuming reporting process, well-known reactions, an uncertain association, what is similar to our results. Of all obstacles mentioned in the survey, respondents have identified two as being the dominant reasons for the failure to report adverse effects, including lack of experience in filling out the ADR reporting forms (71.4\%) and unavailability of ADR reporting forms (72.7\%). Other reasons mentioned in the survey include: the ADR reporting form is too complicated (51.6\%), reporting requires a lot of time $(50.2 \%)$, reporting could show a lack of knowledge (32.3\%), reporting requires the use of my own resources and I am not motivated to do that $(27.6 \%)$, fear of responsibility $(25.6 \%)$ and the position that one case that goes unreported does not make a difference (18.1\%).

According to responses provided by healthcare professionals covered by the survey, non-reporting of adverse effects in $\mathrm{BiH}$ appears to be linked with a lack of knowledge concerning the ADR reporting process and not with the personal and professional characteristics reported in other surveys. The ADR reporting rate can therefore be increased by overcoming the abovementioned obstacles as has been confirmed by certain studies. Some of these obstacles can be addressed by proper management and the promotion of a pharmacovigilance program, and with relevant guidelines that would be available to all. Also there is an urgent need for postgraduate educational programs to emphasize the role and responsibility of the HCP in pharmacovigilance practices, to underline the importance of pharmacovigilance and $\mathrm{ADR}$ reporting. In conclusion, it is necessary to offer continuous educational programs until we reach the point that voluntary reporting of ADRs become customary and habitual among all HCP.

The limitation of this study is the fact that surveyed HCP as well as related institutions and cities, which are randomly selected, do not represent $\mathrm{HPC}$ in all $\mathrm{BiH}$. Another limitation of this study is the answer reliability - inherent problem with surveys and interviews, and whether the responses of HCP are truly representative. Third limitation of study is small number of questions in the survey which evaluated knowledge and perception of PV. Although this study has certain limitations and it would be inappropriate to plan interventions based on the findings of this study alone, however, it does provide an insight into the possible interventions that could be planned in future.

\section{CONCLUSION}

Under-reporting of adverse reactions is a phenomenon present in all parts of the world, this has been confirmed by surveys already conducted, and it can be attributed to all healthcare professionals.

The results of this survey have shown that even though the majority of healthcare professionals have never reported an ADR, although they do have a positive perspective towards pharmacovigilance. The results suggest that $\mathrm{ADR}$ under-reporting is a result of unfamiliarity with the existing reporting system. Regulatory bodies need to improve the management and promotion of the reporting system in $\mathrm{BiH}$ in order to address the issue of healthcare professionals lacking the necessary knowledge on ways to report. It could take a while before healthcare professionals accept ADR reporting as part of their everyday 
practice, but on the long run, this is definitely worth the effort.

\section{COMPETING INTERESTS}

The authors declare no conflict of interest.

\section{REFERENCES}

1. Oshikoya KA, Awobusuyi JO. Perceptions of doctors to adverse drug reaction reporting in a teaching hospital in Lagos, Nigeria. BMC Clin Pharmacol 2009;9:15-20. http://dx.doi.org/10.1186/1472-6904-9-14.

2. Baniasadi S, Fahimi F, Shalviri G. Developing an adverse drug reaction reporting system at a teaching hospital. Basic Clin Pharmacol Toxicol. 2008;102:408-11. http://dx.doi.org/10.1111/j.1742-7843.2008.00217.x.

3. Millar JS. Consultations owing to adverse drug reactions in a single practice. Br J Gen Pract. 2001;51(463):130-1.

4. The Safety of Medicines in Public Health Programmes: pharmacovigilance an Essential Tool. Geneva: WHO;2006.

5. Hazell L, Shakir SA. Under-reporting of adverse drug reactions: a systematic review. Drug Saf. 2006;29(5):385-96. http://dx.doi. org/10.2165/00002018-200629050-00003.

6. Belton KJ. Attitude survey of adverse drug-reaction reporting by health care professionals across the European Union. The European Pharmacovigilance Research Group. Eur J Clin Pharmacol 1997; 52(6): 423-7. http://dx.doi.org/10.1007/s002280050314.

7. Bäckström M, Mjorndal $T$, Dahlqvist R, Nordkvist-Olsson T. Attitudes to reporting ADR in northern Sweden. Eur J Clin Pharmacol 2000; 56: 729-32. http://dx.doi.org/10.1007/s002280000202.

8. Eland IA, Belton KJ, van Grootheest AC, et al. Attitudinal survey of voluntary reporting of adverse drug reactions. Br J Clin Pharmacol 1999; 48: 623-7. http://dx.doi.org/10.1046/j.1365-2125.1999.00060.x.

9. Hasford J, Goettler M, Munter KH, Muller-Oerlinghausen B. Physicians' knowledge and attitudes regarding the spontaneous reporting system for adverse drug reactions. J Clin Epidemiol 2002; 55: 945-50 http://dx.doi. org/10.1016/S0895-4356(02)00450-X.

10. Williams $D$, Feely J. Underreporting of adverse drug reactions: attitudes of Irish doctors. Ir J Med Sci 1999;168:257-61 http://dx.doi.org/10.1007/ BF02944353.

11. Ahmad SR. Adverse drug event monitoring at the Food and Drug Administration: your report can make a difference. J Gen Intern Med 2003; 18:57-60. http://dx.doi.org/10.1046/j.1525-1497.2003.20130.x.

12. Wysowski DK, Swartz L. Adverse drug event surveillance and drug withdrawals in the United States, 1969-2002: the importance of reporting suspected reactions. Arch Intern Med. 2005;165:1363-69. http://dx.doi. org/10.1001/archinte.165.12.1363.

13. Medicinal products and medical devices act. Official Gazette of $\mathrm{BiH} 58 / 08$.

14. Book of rules on the manner of reporting, collecting and following adverse effects of the medicinal products. Official Gazette of BiH 58/12.

15. McGettigan P, Feely J. ADR reporting: opinions and attitudes of medical practitioners in Ireland. Pharmacoepidemiol Drug Saf 1995;4:355-8 http:// dx.doi.org/10.1002/pds.2630040607.

16. Cosentino M, Leoni $O$, Oria $C$, et al. Hospital-based survey of doctors' attitudes to adverse drug reactions and perception of drug-related risk for adverse reaction occurrence. Pharmacoepidemiol Drug Saf 1999;8:S27-35 http://dx.doi.org/10.1002/ (SICI)1099-1557(199904)8:1+<S27:AID-PDS407>3.3.CO;2-H
17. Figueiras A, Tato F, Fontainas J, et al. Physicians' attitudes towards voluntary reporting of adverse drug events. J Eval Clin Pract 2001;7:347-54 http://dx.doi.org/10.1046/j.1365-2753.2001.00295.x.

18. Vallano A, Cereza G, Pedro' s C, et al. Obstacles and solutions for spontaneous reporting of adverse drug reactions in the hospital. Br J Clin Pharmacol 2005;60:653-8 http://dx.doi.org/10.1111/j.1365-2125.2005.02504.x.

19. Herdeiro MT, Figueiras A, Polonia J, Gestal-Otero JJ. Physicians' attitudes and adverse drug reaction reporting: a casecontrol study in Portugal. Drug Saf 2005;28:825-33 http://dx.doi.org/10.2165/00002018-200528090-00007.

20. Chatterjee S, Lyle N, Ghosh S. A survey of the knowledge, attitude and practice of adverse drug reaction reporting by clinicians in Eastern India. Drug Saf 2006;29(7):641-2 http://dx.doi.org/10.2165/00002018-200629070-00009.

21. Toklu HZ, Uysal M.K. The knowledge and attitude of the Turkish community pharmacists toward pharmacovigilance in the Kadikoy district of Istanbul. Pharm World Sci. 2008;30(5):556-62. http://dx.doi.org/10.1007/ s11096-008-9209-4.

22. Scott HD, Thacher-Renshaw A, Rosenbaum SE, et al. Physician reporting of adverse drug reactions: results of the Rhode Island Adverse Drug Reaction Reporting Project. JAMA. 1990;263:1785-8. http://dx.doi. org/10.1001/jama.1990.03440130073028.

23. Bateman DN, Sanders GL, Rawlins MD. Attitudes to adverse drug reaction reporting in the Northern Region. Br J Clin Pharmacol 1992; 34:421-6.

24. Eland I.A, Belton KJ, Van Grootheest AC, Meiners AP, Rawlins MD, Stricker B.H. Attitudinal survey of voluntary reporting of adverse drug reactions. $\mathrm{Br} J$ Clin Pharmacol. 1999;48:623-7 http://dx.doi. org/10.1046/j.1365-2125.1999.00060.x.

25. Serrano Cozar G, Esteban Calvo C, Gijon Porta JA, Vaquero Turiño I, Vázquez Burgos MI, Ibáñez Ruiz C, Frías Iniesta J. Adverse drug reactions and a program of voluntary notification: an opinion survey of primary care physicians. Aten Primaria 1997; 19:307-12.

26. Li Q, Zhang SM, Chen HT, Fang SP, Yu X, Liu D, Shi LY, Zeng FD. Awareness and attitudes of healthcare professionals in Wuhan, China to the reporting of adverse drug reactions. Chin Med J 2004;117:856-61.

27. Mes K, deJong-van den Berg LTW, van Grootheest AC. Attitudes of community pharmacists in the Netherlands towards adverse drug reaction reporting. Int J Pharm Pract 2002;10:267-72 http://dx.doi. org/10.1211/096176702776868460.

28. Houghton J, Wood F, Davis S, Coulson R, Routledge P. Community pharmacist reporting of suspected ADRs: (2) Attitude of community pharmacists and general practitioners in Wales. Pharm J 1999; 263:788-91.

29. Gupta P, Udupa A. Adverse drug reaction reporting and pharmacovigilance: Knowledge, attitudes and perceptions among resident doctors. J Pharm Sci Res 2011;3:1064-9.

30. Ramesh M, Parthasarathi G. Adverse drug reactions reporting: attitudes and perceptions of medical practitioners. Asian J Pharm Clin Res 2009:2:10-4

31. Ghosh S, Ali S, Chhabra L, Prasad C, Gupta A. Investigation of attitudes and perception of medical practitioners on adverse drug reaction reporting - a pilot study. T Ph Res 2010;3:1-9.

32. Green CF, Mottram DR, Rowe PH, Pirmohamed M. Attitudes and knowledge of hospital pharmacists to adverse drug reaction reporting. $\mathrm{Br} J$ Clin Phamracol 2001;51:81-6 http://dx.doi. org/10.1046/j.1365-2125.2001.01306.x.

33. Green CF, Mottram DR, Raval D, Proudlove C, Randall C. Community pharmacists' attitude to adverse drug reaction reporting. Int J Pharm Pract 1999;7:92-9. http://dx.doi.org/10.1111/j.2042-7174.1999.tb00955.x.

34. Rawlins MD. Spontaneous reporting of adverse drug reactions I: the data. $\mathrm{Br}$ J Clin Pharmac 1988;26:1-5. http://dx.doi.org/10.1111/j.1365-2125.1988. tb03356.x. 